\title{
Fronteiras Correspondidas: Moisés Bertoni e Suas Cartas
}

\author{
Fronteras correspondientes: Moisés Bertoni y sus Cartas \\ Corresponding Borders: Moisés Bertoni and His Letters
}

\author{
Solange da Silva Portz ${ }^{1}$ \\ Valdir Gregory ${ }^{2}$
}

\begin{abstract}
Resumo
O presente trabalho constitui-se em uma pesquisa em torno de cartas remetidas e recebidas por Moisés Santiago Bertoni. Tem como objetivo lançar olhares sobre o mundo da fronteira trinacional Brasil, Paraguai e Argentina, final do século XIX e início do XX. Estes documentos apresentam acontecimentos e vivências ausentes em outras fontes de consulta. Bertoni, ao longo de sua vida, elaborou uma prática de produção sobre si, que englobou um diversificado conjunto de ações, desde as ligadas à escrita de si, até aquelas chamadas memórias de si. Essa "escrita de si" está sendo entendida dentro de um contexto de relações com seus próprios documentos, pois deixaram aparente o envolvimento que ele mantinha com os registros que produziu e arquivou para a construção de memórias que o colocam em uma posição de centralidade na fronteira. Foram os indícios contidos nas cartas que possibilitaram o relevante estudo não só sobre o personagem Bertoni, mas também sobre suas vivências e o rico legado produzido por ele e suas relações fronteiriças.
\end{abstract}

Palavras-chave: Moisés Santiago Bertoni; Fronteiras; Cartas; Escrita de Si.

\section{Resumen}

El presente trabajo consiste en una investigación en torno a las cartas enviadas y recibidas por Moisés Santiago Bertoni. Tiene como objetivo dar una mirada al mundo de la frontera trinacional Brasil, Paraguay y Argentina, a finales del siglo XIX y principios del XX. Estos documentos presentan hechos y experiencias ausentes de otras fuentes de consulta. Bertoni, a lo largo de su vida, desarrolló una práctica de producción sobre sí mismo, que englobaba un conjunto diverso de acciones, desde las relacionadas con la escritura de sí mismo, hasta las llamadas memorias de sí mismo. Esta "escritura de si mismo" se está entendiendo en un contexto de relaciones con sus propios documentos, pues evidenciaba el involucramiento que mantenía con los registros que producía y archivaba para la construcción de memorias que lo colocaban en una posición central en la frontera. Fueron las evidencias contenidas en las cartas las que posibilitaron el relevante estudio no solo sobre el personaje de Bertoni, sino también sobre sus vivencias y el rico legado producido por él y sus relaciones fronterizas.

Palabras Clave: Moisés Santiago Bertoni; Frontera; Cartas; Escrita de si.

\begin{abstract}
The present work consists of a research around letters sent and received by Moisés Santiago Bertoni. It aims to take a look at the world of the tri-national frontier Brazil, Paraguay and Argentina, late 19th and early 20th centuries. These documents present events and experiences absent from other sources of consultation. Bertoni,
\end{abstract}

\footnotetext{
${ }^{1}$ Doutora em Sociedade, Cultura e Fronteira; Universidade Estadual do Oeste do Paraná; Foz do Iguaçu, Paraná; Brasil; solimagem22@gmail.com.

${ }^{2}$ Doutor em História; Professor Sênior da Universidade Estadual do Oeste do Paraná; Foz do Iguaçu, Paraná, Brasil; valdirmacgregory@gmail.com.
} 
throughout his life, developed a production practice about himself, which encompassed a diverse set of actions, from those related to the writing of himself, to those called memories of himself. This self-writing is being understood within a context of relations with his own documents, as it made apparent the involvement he maintained with the records he produced and archived for the construction of memories that put him in a central position on the border. It was the evidence contained in the letters that enabled the relevant study not only about the character Bertoni, but also about his experiences and the rich legacy produced by him and his border relations.

Keywords: Moisés Santiago Bertoni; Borders; Letters; Self-writing. 


\section{Introdução}

Fronteiras correspondidas intitula este texto elaborado a partir de cartas escritas, lidas e arquivadas por Moisés Santiago Bertoni no final do século XIX e início do século XX. Nascido na Suíça, Bertoni migrou para a América do Sul em 1884. Morou na Argentina entre 1884 e 1887, no Paraguai de 1887 até sua morte, em Foz do Iguaçu no ano de 1929. Foi pesquisador e construiu uma rede de relacionamentos com pessoas das mais variadas nacionalidades, formações e atuações.

As correspondências conservadas em Puerto Bertoni até a década de 1990, depois inventariadas, organizadas e transferidas para o Archivo Nacional de Asunción, somam mais de 4000, produzidas entre o período que antecede sua chegada à América do Sul. Esse conjunto de documentos possui um catálogo de consulta, a partir do qual, é possível ter acesso aos nomes, assuntos e datas das cartas, uma riqueza histórica e cultural.

De forma inédita, lança-se olhares sobre um pequeno conjunto desses registros e refletir sobre o que tais cartas dizem sobre o contexto de sua produção. Tais registros revelam acontecimentos e vivências ausentes em outras fontes de consulta, considerando-se tratar de documentos pouco explorados em pesquisas sobre a Tríplice Fronteira.

A metodologia deste trabalho está baseada na leitura de cartas, seleção de informações no que se refere à vida de personagens para refletir sobre a "escrita de si, jogando luz sobre novos elementos para estudos. Tais reflexões fundamentam-se a partir das contribuições de Carlo Ginzburg, buscando nos rastos deixados pelo personagem indícios sobre as vivências no contexto da fronteira.

As correspondências que Bertoni remeteu, recebeu e arquivou são documentos para pesquisa, na medida em que permitem discutir ideias, opiniões, conhecimentos, negociações e trocas de favores. Cartas publicadas em jornais que anunciam a chegada de Bertoni na América do Sul em 1884, outras que noticiam sua partida em 1929. Cartas cujo tema são as próprias cartas. Cartas que falam de amor, esperança, tristeza, desilusão e decepção. Nas "escritas de si", era constante a jornada rumo à busca pela felicidade na fronteira. Correspondências que nos levam a seguir viagem para conhecer um mundo no qual o extraordinário está nas relações científicas, de amizade, de trabalho e de família.

Na apresentação do catálogo de consulta do Archivo Nacional de Asunción, os autores Baratti e Candolfi informam sobre como encontraram as correspondências em Puerto Bertoni na década de 1990. Observaram que estavam arquivadas a partir de um critério usado por 
Bertoni, que ordenou as cartas por letras maiúsculas, como por exemplo: $\mathrm{F}=$ família, $\mathrm{K}=$ contas, $\mathrm{C}=$ científica, $\mathrm{P}=$ publicações. No entanto, apenas parte desse conjunto estava sujeita a essa ordem, pois parecia que o próprio Bertoni, às vezes, tinha dúvidas sobre a colocação e ordenação das cartas, que terminavam com duas ou três siglas. Nos primeiros anos, foram arquivadas por ordem cronológica, outras vezes de acordo com uma ordem alfabética e, só mais tarde, de acordo com a classificação temática. Em alguns registros, verificou-se a participação de sua esposa Eugenia na organização e guarda das cartas.

O catálogo apresenta uma lista de abreviações com o objetivo de facilitar a localização para consulta. Encontra-se organizado a partir do levantamento documental do arquivo de Bertoni, apresenta um índice detalhado, no qual estão registrados os números de páginas, datas, locais e destinatários das cartas. Esta forma de organização foi crucial e facilitou o acesso amplo ao conjunto de cartas.

Destaca-se o cuidado dos organizadores com as folhas soltas ao inventariá-las minuciosamente de forma cronológica. Também foram discriminadas quanto aos seguintes aspectos, se eram manuscritas, originais, cópias ou rascunhos. As cartas da família, dirigidas a Bertoni, foram ordenadas cronologicamente em pastas. Desta forma, algumas correspondências especiais estão separadas, pela sua importância no contexto de suas relações científicas e humanas. Está organizado com um índice sintético e um índice geral, seguido pelos índices de cada caixinha, que por sua vez abriga as pastas. Outra parte das correspondências está arquivada no Museo Della Valle di Blenio na Suíça e estas foram transcritas por Baratti \& Candolfi (1999).

O conjunto é por si só significativo, mesmo que as informações sobre o personagem sejam indiretas, já que parte das cartas são destinadas a Bertoni e não remetidas por ele. Tais elementos constituem-se em subsídios para levantar-se, ilustrar e analisar as vivências de Bertoni. É tentador verificar em que medida esses documentos podem esclarecer seu papel social, mesmo que, em muitos registros, não seja encontrada correspondência ativa de Bertoni. Ainda assim, é possível perceber suas ações e posturas, através de comentários feitos e respostas a suas perguntas nas cartas recebidas.

\section{Moisés Bertoni e a "escrita de si"}

Escrevem-se cartas para pessoas especiais. Elas possuem significado para quem escreveu e para quem as leram. Este aspecto fornece indícios sobre o pensamento de Bertoni, sobre uma "escrita de si". 
Neste sentido, Gomes (2004) observa e considera que não são muito frequentes pesquisas que se concentram na exploração da escrita de correspondências. Embora esse tipo de documentação tenha sido usado como fonte, é recente sua tomada como fonte privilegiada, principalmente tomada ela mesma como objeto de pesquisa. "Uma inflexão que passa a requerer maiores investimentos em sua utilização e análise, ou seja, maiores cuidados teóricometodológicos" (GOMES, 2004, p.10). A autora denomina essa prática como sendo a escrita de si, que teve seu apogeu no século XIX, momento da institucionalização dos museus e o aparecimento do romance moderno, no qual, o sujeito se viu dotado de direitos civis e políticos no contexto vivido pela sociedade daquele período. Trata-se de um processo longo a respeito para incorporação deste tipo de fonte para pesquisa. Mas, que vem sofrendo transformações atualmente nas Ciências Humanas. Em um primeiro momento, com o telefone e mais recentemente com o e-mail e o WhatsApp. Escrever cartas é uma prática antiga, mas "seu significado ganha contornos específicos com a constituição do individualismo moderno... é a emergência histórica desse indivíduo nas sociedades ocidentais" (GOMES, 2004, p.11).

As correspondências abordam a vida de Bertoni, aproximando-o da sua esfera privada, mas também a relação que mantinha com o espaço público. "O documento não trata de dizer o que houve, mas de dizer o que o autor diz que viu, sentiu e experimentou, retrospectivamente, em relação a um acontecimento", (GOMES, 2004, p.14). Isso está presente nas cartas escritas por Bertoni. Deve-se levar em conta, ao trabalhar com esse tipo de documentação, determinadas características, como as relações do texto com o autor, seus objetivos e perspectivas na construção voluntária ou involuntária do "eu". Também atentar-se para uma série de questões que não envolvem apenas o indivíduo "autor" da carta, mas também a relação que se estabelece com o "receptor", a quem se escreve (GOMES, 2004, p.10-22).

Nas correspondências do século XIX, as formas de tratamento são entendidas enquanto estratégias de polidez, a fim de preservar a própria face e a do outro. Nas cartas enviadas e recebidas por Bertoni, destacam-se as formas de tratamento. O papel da carta com o timbre de alguma empresa, as formas de tratamento são recursos que, conforme Matos e Grinberg, funcionam enquanto estratégias para evitar conflito. "Assim é preciso lidar com a preservação pessoal e o modo como se é visto socialmente" (MATOS \& GRINBER, 2004, p.31). Nos registros consultados, a forma de tratamento já se encarrega de expressar um tom respeitoso ao denominar Bertoni de Doutor, acompanhado do sobrenome. Fica expresso como ele era visto no meio político, intelectual e econômico. Nas cartas que remetia, também seguia 
um padrão formal. Mas é nas endereçadas à família e aos amigos, com tratamento menos formal e mais amigável, que vemos um Bertoni amoroso e apaixonado.

Nas cartas de Moisés Bertoni, enviadas e recebidas entre família, amigos, intelectuais, comerciantes e políticos, estão explícitas suas relações de amizade, trabalho, ideias, projetos, opiniões, interesses, sentimentos e desilusões. Redes de sociabilidade que possibilitam conhecer um pouco do "mundo na fronteira" através das relações estabelecidas em espaços privados e públicos. Permitem ainda vislumbrar que se comunicar por cartas na fronteira era um ato cerimonioso. Seja pelas formas pronominais de tratamento em tom de formalidade adotadas na escrita, seja pela espera dos vapores que atracavam no Porto Bertoni, que levavam e traziam as notícias. Conhecendo o caminho que liga o porto do rio Paraná à casa de Bertoni, é possível imaginar o trajeto que era percorrido com as correspondências na estreita trilha. Bertoni, através da pequena janela de seu escritório, assistia à movimentação de embarcações. Este é um cenário imaginário e reforçado pela autora ao fazer o cruzamento entre as fontes escritas e visuais. Nas fotografias consultadas, foi possível visualizar que a vegetação entre a casa de Bertoni e as barrancas do Rio Paraná propiciavam esta contemplação. Haja vista a posição da casa, a localização da janela e o campo de visão de Bertoni.

Era a esposa que separava e distribuía as correspondências. Bertoni selecionava o que seria lido por primeiro. Tanto o ato de escrever, como ler, envolvia a capacidade de expor em palavras, opiniões, queixas, satisfações, encantos e esperanças. A prática de escrever cartas fazia parte do cotidiano do personagem e de sua família. A preocupação que tinha em arquivar nos leva a refletir sobre a importância que ele próprio dava aos seus registros que documentam seus feitos e que poderiam no futuro lhe conferir a importância que considerava ter. Pois em uma delas ele orienta sua esposa Eugenia:

Dedica una parte de tu tiempo a poner en orden aquella correspondencia, preciosa reliquia, testimonio sin igual, que debemos conservar como objeto sagrado, pues lo es, si algo sagrado hay. Será un nuevo e indecible placer y un deber cumplido (Moisés à Eugenia, 11 de novembro 1922).

Essas palavras demonstram o valor que Bertoni atribuía às cartas. Também manifestam a necessidade da preservação, elevando as mesmas a uma categoria documental, tendo uma preocupação em registrar, conservar, preservar, organizar e arquivar. Por outro lado, deixou nítida a importância dada às relações com os remetentes, em difundir os conhecimentos adquiridos a partir de suas pesquisas, principalmente agrícolas e sobre a sociedade Guarani. Não eram cartas que traziam ou levavam somente notícias, mas estavam 
cheias de informações sobre o contexto em que foram escritas. Bertoni chamava as correspondências de Relíquias Preciosas e Objetos Sagrados, indicando, assim, o valor atribuído às mesmas. Pois, nas cartas remetidas, principalmente a familiares, observou-se que concebia as mesmas como instrumento de registro de suas viagens e outros feitos, até como notas fiscais de produtos vendidos e adquiridos, valores a receber e a pagar, entre outros.

Através de cartas, pode-se conhecer a trajetória individual do personagem, com um percurso que se altera ao longo do tempo, desde a chegada a Misiones na Argentina, passando pelas dificuldades vividas em Yguarazapá no Paraguai, até o deslumbre com a propriedade Puerto Bertoni e as dificuldades no fim da sua vida. Perceber que o mesmo período da vida de uma pessoa pode ser apresentado em tempos com ritmos diversos. Ou seja, o tempo da casa, o tempo do trabalho, o tempo da pesquisa, o tempo da espera das cartas, o tempo do plantio e o tempo da colheita. Bertoni constrói identidade para si e, ao buscar registrar sua vida, apresenta-se além daquele pesquisador e cientista. Mostra-se ser marido romântico, pai amoroso, amigo fiel, agricultor preocupado com o manejo da terra, comerciante e exportador de produtos agrícolas. O cotidiano de homem que manifestava na palavra escrita os sentimentos de saudades, preocupações, insatisfações, decepções e alegrias. Esses registros permitem conhecer uma produção de si, um Bertoni, no individual, que ganha valor ao analisarmos o todo - o contexto. Ou seja, as cartas apresentam a trajetória individual do personagem, mas também permitem analisar as redes de sociabilidade construídas.

Considerando a rede que Bertoni estabeleceu a partir da e na fronteira, ele não era um personagem anônimo. Como cientista, fazia questão de compartilhar e divulgar os resultados de suas pesquisas além mar. Já nas relações familiares, mesmo distante, se fazia presente, com informações sobre as atividades realizadas na colônia. A prática da escrita era estimulada entre os membros da família. O conjunto de cartas, possibilita visualizar a rede de relações que Bertoni construiu, apresentadas na forma de relações familiares, comerciais, científicas, políticas e de amizade.

As cartas são registros que refletem ele no espaço público, percebe-se um Bertoni detalhista na descrição minuciosa de eventos, o que denota o compromisso de registrar o que via e sentia. Tinha um cuidado em manter constantes contatos, em alimentar as relações em sua rede de sociabilidade.

Mesmo sem consultar todo o conjunto de cartas que estão guardadas no arquivo em Assunção - PY, o quadro que apresenta temas e nomes permitiu formular a hipótese inicial de que tais correspondências exerceram um papel importante e fundamental para conhecer as relações de Bertoni na fronteira, seja nas pesquisas científicas, na divulgação e na troca de 
experiências com outros pesquisadores; seja nas relações comerciais, para a exportação dos produtos cultivados na colônia, ou ainda, nos contatos na esfera política do Paraguai e da Argentina. Relações essas que geraram discussões sobre os rumos da agricultura na fronteira e a constante busca por apoio para publicações de seus registros.

Percebe-se um Bertoni pesquisador, com capacidade de reunir em torno de si uma rede de pessoas das mais variadas nacionalidades, formações e atuações. As correspondências que remeteu e recebeu são documentos para o pesquisador, na medida em que possuem ideias, opiniões, conhecimentos, negociações e trocas de favores. Nesse sentido, emissores e receptores construíram um universo complexo de registros subjetivos sobre vivências, redes, sociabilidade, significados que podem ser pesquisados para debater uma infinidade de temas.

Estudar correspondências significa considerar toda uma rede de relações em torno da construção de uma carta. Constroem-se redes onde pessoas são envolvidas, o escritor e o receptor, os leitores, os que são mencionados, os que as transportam e entregam. "Conhecer esses sujeitos permite ao historiador traçar um quadro mais amplo das relações estabelecidas entre eles e, desse modo, perceber a carta como parte de uma rede de contatos" (BEZERRA, 2009, p.136). Assim, há de se considerar todo um circuito que envolve atores sociais, a materialidade das cartas, anotações, anexos e materiais junto com as cartas. Também formas de tratamento e sentimentos expressos.

Para Silva (2011, p.341), esse tipo de registro é capaz de revelar parcelas desconhecidas ou até então invisíveis da história e do mundo social vivenciado pelos interlocutores. Esse "material foge aos rigores institucionais da produção documental, às características seriais e ao formato burocrático, e tem uma origem privada, um caráter pessoal". Martins entende que:

\footnotetext{
Em alguns casos a carta pode fornecer algumas informações que faltavam na tessitura do passado, em outros, ela não teria o poder de revelar "verdades ocultas" por trás do véu das aparências por pertencer ao campo do imaginário, do discurso, da subjetividade ... com suas variadas formas, faz parte dos gêneros discursivos ... e é tão rica e diversa quanto as possibilidades humanas são inesgotáveis (MARTINS, 2011, p.5).
}

Francisco Ribeiro da Silva, num "estudo e análise crítica das cartas" remetidas ao militar português Coronel Helder Ribeiro, afirma que a leitura das cartas apontou para algumas ideias: "protagonismo político-militar", “extraordinário prestígio”, “carisma e sedução da sua personalidade". Observa, ainda, que a correspondência recebida subentende a alteridade, a interação (SILVA, 1997 p.7-8). Cartas trocadas entre particulares exprimem: 
Sentimentos de amor, de amizade ou (raramente) de ódio, transmitem pedidos de favores ou agradecem graças recebidas, revelam novidades ou intrigas, veiculam votos de pesar ou de felicitações, constituem quase sempre demonstração de ligações afectivas. Mas podem também guardar relatos sobre ocorrências diversas, talvez interesses para quem são endereçadas ou testemunhar directa ou indirectamente velhas e novas cumplicidades. Algumas conseguem captar reflexos do sentir popular perante acontecimentos nacionais ou internacionais. Queixas, denúncias, lisonjas - afinal tudo cabe numa simples carta (SILVA, 1997, p.13-14).

Através das cartas de Bertoni, apresentadas no catálogo e da pequena amostra que foi $\operatorname{lida}^{3}$, percebeu-se dois tipos de produção da escrita de si. A primeira ligada diretamente à escrita que apresenta um personagem dotado de conhecimento, sonhos e perspectivas, capaz de expor seus sentimentos mais íntimos. A segunda produção refere-se à constituição de uma memória de si, concretizada pela organização e guarda de correspondências pelo próprio Bertoni e mais tarde pelo Archivo Nacional de Asunción. Tais registros revelam uma rede de comunicações, o local dos remetentes, o conteúdo, traços do caráter (SILVA, 1997, p.14-15). Constitui-se na materialização da vida do personagem e das pessoas com quem se relacionava. Fica evidente a importância em dar significado ao mundo do personagem, relacionando-o com sua própria vida. Isso fica manifesto nas cartas em que canta amor ao Paraguai e as suas desilusões no alvorecer do século XX.

Tendo em vista o conjunto das correspondências, foi feita uma distribuição por temáticas. Os temas mais presentes foram identificados como: família, trabalho, ciência, amigos. Com eles foram relacionados nomes que mais apareceram. É importante ressaltar que esses grupos possuem relações entre si. A partir desses dados extraídos do catálogo de consulta, foi organizado o quadro a seguir.

Quadro 1: Temas e nomes

\begin{tabular}{|l|l|}
\hline Família & $\begin{array}{l}\text { Eugênia, esposa; } \\
\text { Brenno Irmão; } \\
\text { Filhos e sobrinhos. }\end{array}$ \\
\hline Trabalho & $\begin{array}{l}\text { H. Kraus de Asunción; } \\
\text { M. Brossa de Asunción; } \\
\text { Domingos Barthes da Posadas; } \\
\text { Nuñez Y Gibaja Posadas; } \\
\text { Cooperativa Ayala Y Veja de Encarnación. } \\
\text { Eusebio Ayala, presidente do Paraguai (1921-1923). }\end{array}$ \\
\hline Ciência & $\begin{array}{l}\text { Carlos E. Porter, professor de Ciências Naturais, de Santiago Chile; } \\
\text { Hermann Von lhering, Médico, Zoólogo, Santa Catarina; } \\
\text { Félix Daumas Ladouce, escritor. }\end{array}$ \\
\hline Amigos & $\begin{array}{l}\text { Leopoldo A. Benítez, Agrônomo e docente da escola de Agronomia de Trindad (fundada por Bertoni); } \\
\text { Rodolfo Ritter escritor intelectual, (considerado um dos melhores amigos de Bertoni; }\end{array}$ \\
\hline
\end{tabular}

\footnotetext{
${ }^{3}$ Um conjunto de 138 cartas podem ser consultadas na biografia de Bertoni BARATTI\& CANDOLFI (1994).
} 
Adolf Niklaus Schuster, médico, antropólogo e filósofo.

Fontes: Baratti \& Candolfi (1994 e 1999) e Catálogo do Archivo Nacional de Asunción. Organização dos autores.

As correspondências do grupo familiar (família) estão organizadas por ordem cronológica no arquivo e se configura em um número significativo, incluindo familiares da Europa, esposa, filhos, genros, sobrinhos, netos... As trocas de correspondências de familiares, utilizadas nesta pesquisa são as que se encontram destacadas na biografia de Baratti e Candolfi (1994, 1999); Ramella (1985) e Schrembs (1984), visto que parte das correspondências familiares se encontra em arquivo na Suíça ${ }^{4}$.

Os registros que fazem referência a amigos e à ciência estão inter-relacionados, pois parte das cartas enviadas para amigos, referem-se a publicações e trocas de informações sobre as pesquisas científicas, além de conterem informações sobre os familiares. Através das correspondências enviadas para a esposa, para amigos e para o irmão Brenno, pode-se conhecer certos aspectos da vida de Bertoni. As correspondências são tomadas como uma documentação rica que apresentam detalhes de suas vivências. Por exemplo, na carta escrita na primavera de 1875, Moisés fala com sua família sobre seus projetos com Eugenia e a introduz na casa como noiva. Sua mãe e Eugenia imediatamente se tornam amigas, tanto que a sogra escreve para sua futura nora.

Minha amada Eugenia! Com quanta alegria recebi seus carinhos e os do meu querido Moisés ... Portanto, você faz a felicidade do meu Moisés e minha ao mesmo tempo, e eu sempre a amarei enquanto eu estiver viva ${ }^{5}$, (Giuseppina a Eugenia Apud SCHREMBS, 1984, p.14).

O pai de Bertoni não via motivos para apressar o casamento. Não seria apenas uma questão de idade, mas também de dinheiro. A manutenção das crianças para estudar custaria dinheiro, dívidas se acumulariam e várias empresas que tentaram melhorar a situação não dariam os resultados esperados. Entre alianças, dotes, enxoval, almoço e várias despesas, esse casamento pesaria para a família. No entanto, se há uma coisa que não falta em Bertoni é a obstinada teimosia e em quatro de janeiro Moisés se casou com sua amada Eugenia.

Quando ainda estava na universidade, cursando direito em Genebra, enviava cartas de amor a Eugenia. Manifestando os dias cinzentos do outono, descreveu momentos de angústia

\footnotetext{
${ }^{4}$ http://www.mosebertoni.ch/index.php?m=6\&s=1.

5 Tradução livre. Mia diletta Eugenia! Con quanto giubilo ho ricevuto le carissime sue e quelle del mio caro Mosè ... Ella pertanto fa la felicità del mio Mosè e la mia ad un tempo, ed io pure l'amerò sempre finché avrò vita (Giuseppina a Eugenia Apud SCHREMBS, 1984, p.14).
} 
e em primeiro de dezembro, em um momento em que a família se esforçava em atrasar o casamento, para que ele primeiro finalizasse os estudos, escreveu:

Oh Eugenia, uma arma já estava perto da minha têmpora, um passo muito próximo que me levaria mil milhas de distância de você, eu vi a morte perto de mim! ... Memórias horríveis! Quem me salvou foi apenas o pensamento do seu destino (Bertoni a Eugenia $1^{\circ}$ de dezembro,1876. Apud SCHREMBS, 1984, p.27).

Esse amor manifesto aparece também em outras cartas, juntamente com as queixas de estar enfermo. A causa principal da enfermidade estaria, provavelmente, na distância que os separava. A carta é "um objeto que busca a aproximação de sujeitos distanciados - surge aqui, mais uma vez, como minimizadora de distâncias, possibilitando o diálogo entre autores-obras afastados por circunstâncias diversas” BEZERRA, 2009, p.146).

Esse contexto em que Bertoni expressa esse apelo sentimental, a ponto de pensar em suicídio, gera algumas reflexões relacionadas ao contexto cultural no qual Bertoni estava inserido. É bem provável que Bertoni pudesse ter sofrido influência da escola literária que predominava no cenário cultural na Europa. Suas ideias românticas e a manifestação de um amor platônico poderia ter como base o Romantismo, que tinha como um de seus precursores Goethe, com o romance Os sofrimentos do jovem Werther, publicado na Alemanha em 1774, referência de leitura entre os jovens europeus do século XIX. Obra que despertou a literatura mais subjetiva e fez parte da transição da escrita centrada na racionalidade para a escrita Romântica. Essa fase foi marcada por um afloramento das questões individuais, dos sentimentos e o subjetivismo, os tons melancólicos, os romances avassaladores ou trágicos, os exageros das emoções, a natureza vista como extensão do eu, foram algumas das características principais desse momento artístico (TEIXEIRA, 2013).

Em outra carta, fica manifesto que a migração para a Argentina fez Bertoni registrar preocupações com a sobrevivência da família. Os dias vividos estão registrados em cartas enviadas para a família na Suíça.

(...) nuestra vida fue tal cadena de sufrimientos que poco nos faltó para caer en la locura. Hemos pasado por todo lo que tiene de difícil la existencia humana. La perfidia humana, la falta de un techo, la miseria más absoluta, la intemperie... Hemos luchado con ánimo de hierro, hemos soportado todo asombrádonos de nosotros miesmos. (BERTONI, carta 6 de Maio de 1985, Apud BARATTI \& CANDOLFI, 1999, p.43).

A mãe, Giuseppina também enviava correspondências ao marido na Suíça. A partir do que escreveu, é possível verificar a mudança vivida pela família (BARATTI \& CANDOLFI, 1994 e 1999; RAMELLA, 1985; SCHREMBS, 1984). Mas será que também foram decisivos para a mudança na ideologia de Bertoni? 
Pero este abandono, o mejor dicho, traición, de los Socios nós já reportado una incalculable vantaje; a saber, que Moisés há sanado completamente de sus ideas Humanistas y Socialistas, y de ahora en adelante se pasará al otro bando y no pensará más que en el próprio interés! Cuántos agravios tuvo que sufrir para curar de sus ideas anteriores! Pero visto de ese lado, há sido una verdadeira suerte (Giuseppina a Ambrogio, 21 de julho de 1984, Apud BARATTI \& CANDOLFI, 1999, p.43).

Mas se engana Giuseppina quando acredita que o filho "no pensará más em en el próprio interes". Em outra carta endereçada ao marido, em outubro do mesmo ano, se queixa que Bertoni só semeia para os estudos, pois trouxe para a América mais de novecentas espécies de plantas para aclimatar. Na carta, fica evidente a indignação da mãe, por não poder criar galinhas, pois estas destruíram as experiências do filho: "por causa de esse bendito jardín de aclimatación no podemos tener gallínas" (Giuseppina a Ambrogio, 25 de outubro de 1985. Apud BARATTI \& CANDOLFI, 1999, p.48).

Bertoni também deixa expresso seu sentimento ao escrever:

Que si yo hubiese podido consagrarme enteramente, como pude hacerlo un simple colono, a satisfacer las necesidades de la vida material, a buen seguro que hubiese podido pasar días felices en el retiro de una paz profunda, de una vida simples y bela que muchisimos me evidiarían. Pero yo no podia gozar esta felicidade. La inmensa naturaleza que se expedía ante mis ojos como una provocante sirena me invitaba a gozar de sus belezas (La Voce del Ticino, 4 de abril de 1886. Apud BARATTI \& CANDOLFI, 1999, p.45).

Para Bertoni a ciência está em primeiro lugar e se pudesse ter se consagrado inteiramente como um simples colono e satisfazer as necessidades da vida material, poderia ter passado dias mais felizes. Em meio à natureza, declara ter se jogado ao convite para a investigação. Por outro lado, o que o atormentava era, antes de qualquer coisa, ter que prover as necessidades da família.

\footnotetext{
Os dias eram cada vez mais difíceis em Yabebyry, a família passava mais de um mês armada para se defender de constantes ataques de bandidos. Os cultivos foram ameaçados pelo gado dos vizinhos que entrou pelo cercado improvisado (Bertoni a Juan Bernasconi e sócio, 16 de junho de 1887, Apud BARATTI \& CANDOLFI, 1999, p.49).
}

Baratti e Candolfi informam que Bertoni correspondeu-se com membros de uma sociedade de emigrantes tesinenses em Buenos Aires. O coordenador da sociedade era Juan Bernasconi, na ocasião sub-gerente do Banco da Italia y Rio de la Plata. Outro sócio que se correspondeu com Moisés foi Giusepe Luraschi, que trabalhava com fabricação de móveis de madeira. Moisés recebeu apoio financeiro do grupo para levar adiante os cultivos experimentais. Em outubro de 1886, o grupo decidiu adquirir terras no Paraguai e o convidou para fazer o reconhecimento e avaliação da área, viagem que aconteceu em agosto do ano 
seguinte. Na ocasião, enviou cartas aos sócios informando sobre sua avaliação, dizendo que aquelas são as melhores terras de toda costa do Paraguai. E aproveitou para fazer o mapa topográfico do Rio Paraná.

Depois de conhecer as terras, estava convencido de que o seu futuro seria em solo paraguaio. A família saiu em fuga para o Paraguai, provavelmente entre novembro 1987 e janeiro de 1988.

Em Yguarazapá, seguiu o projeto de colonização, expondo aos sócios vantagens de ter uma colônia particular e livre. "Piensa cultivar ... y propone a los socios un detalhado presupuestro para un asentamiento de 100 familias sugiriendo comenzar sólo con 50, o también con 25" (Bertoni à Juan Bernasconi 3-6 de agosto de 1887, Apud BARATTI \& CANDOLFI, 1999, p.53-54). Na carta escrita ao sócio, propôs cultivar vários produtos agrícolas, considerou a hipótese de organizar uma redução indígena. Em meio aos indígenas, Bertoni pensou ser um local ideal para iniciar as pesquisas, sentia-se seguro de que a colônia iria prosperar.

No mês de março de 1889, viajou para Buenos Aires para se encontrar com os sócios, firmando um convênio. Seis meses mais tarde, outra carta solicitou a exclusividade na atividade de extração da madeira. "El sacrificio que le pido (siempre que así se pueda llamar) es que dedique todo digo todo su tiempo para acelerar en cuanto sea posible la expedición de las maderas" (José Luraschi a Bertoni, 31 de agosto de 1889. Apud BARATTI \& CANDOLFI, 1999, p.55). No decorrer dos meses, os sócios escreveram manifestando insatisfação com o desenvolvimento do trabalho de extração de madeira. Com isso, aumentou a tensão.

Em abril de 1890, Bertoni renunciou à sociedade em uma carta, dizendo estar insatisfeito com a atividade que vinha desenvolvendo. Preferiu retirar-se e dedicar-se a sua chácara e às pesquisas: "nuevo Robinson, viviendo de mi trabajo y buscando en la quinta del pobre aquel descanso que tanto necesita mi moral quebrantada" (Bertoni a Luraschi, 2 de abril de 1890, Apud BARATTI \& CANDOLFI, 1999, p.57). Ele não recebeu as terras prometidas. E, em escritos posteriores, resumiu com amargura aqueles dias vividos em Yguarazapá, dizendo: "Tres años de prisión incomunicada". Este período foi denominado pelo próprio Bertoni como infames mistérios de Yguarazapá. Alegou que correspondências chegavam abertas. Em várias cartas pesquisadas, há obscuras alusões a situações de perigo com que a família se deparava. Também há relatos sobre dificuldades de comunicação com o exterior. 
Percebeu, também, que a felicidade não estaria na organização de uma colônia, tanto que, ao receber o convite do General Egusquiza, presidente do Paraguai (1894-1898), para assumir a docência e a direção da Escola Nacional de Agricultura em Assuncón, Bertoni propôs uma troca. Aceitaria o convite, mas ficaria livre do compromisso de colonizar as terras de Guilhermo Tell. Para isso teve que viver uma temporada em Assunción. Em carta enviada para sua esposa Eugenia, comunicou o acordo que permitiria tornar-se um proprietário. “...hay otra notícia que más te alegrará: el Presidente ha hecho lugar a mi solicitud, y ha ordenado se me otorguen los títulos de propriedad definitiva del territorio de la Colonia! ... Ahora podemos exclamar, Eureka!" (Bertoni, carta para Eugenia, 9 de maio de 1896). As terras adquiridas passaram a ser seu laboratório científico, para dedicar-se à pesquisa e à produção agrícola. No ano de 1895, enquanto a família iniciava os trabalhos na colônia, Bertoni estava em Assunción para assumir a direção da Escola Nacional de Agricultura.

E em maio de 1913, enviou notícias tranquilizadoras ao seu irmão Brenno.

Puerto Bertoni vai bem. O comércio de frutas e o preço das terras aumentaram. Como você vê, o tempo de colheita de milho já começou, o trabalho é difícil! muito melhor; estamos apenas mais satisfeitos ${ }^{6}$ (Bertoni, Apud BARATTI \& CANDOLFI, 1999, p. 261).

Era ali, junto com a produção agrícola, que desenvolvia seus estudos científicos sobre o povo Guarani e as espécies de plantas no seu jardim de aclimatação, aliando trabalho agrícola e ensino. Mas, esse entusiasmo não durou muito. Puerto Bertoni entrou em crise! Será que parte dessa crise poderia ter sido provocada pela fronteira, lugar que anos antes era visto como território de oportunidades? Com a lei da cabotagem que proibia a exportação dos produtos e o inverno rigoroso, Bertoni perdeu praticamente toda a produção de café e de banana. Destaca-se também o "abandono" dos filhos das terras do pai.

Em outras cartas, Bertoni se mostrou desanimado, em parte, porque depositou grandes esperanças em um projeto ferroviário que deveria impulsionar o setor econômico em Alto Paraná e Puerto Bertoni. Na obra Ferrocarril, Herken (1984) explica que a estrada de ferro que ligaria Asunción a Santos no Brasil, era um projeto conhecido como el Ferrocarril TransParaguayo, que abriria uma saída para o Atlântico, em parceria com o sistema férreo Brasileiro iniciado no final do século XIX, mas que só teve sua concessão autorizada em 1909. Tal estrada passaria nos fundos da propriedade de Bertoni.

\footnotetext{
6 Puerto Bertoni va bien. Le commerce des fruits et le prix des terres augmentent ... Comme tu vois, le temps de récolter a commencé, mais la corvée a été dure! tant mieux; on n'en est que plus satisfaits, (Bertoni, Apud BARATTI \& CANDOLFI, 1999, p. 261).
} 
Um ano antes de sua morte, Bertoni escreveu ao seu filho Reto. Estava desolado, Puerto Bertoni está em ruínas:

Pedidos que no puedo hacer, cuentas que no puedo pagar, miserias en casa, privaciones para mi gente que son las que más me apenan, un peón sólo para todas las 5 hectáreas de quinta y mandiocales y servicios de casa, el monte que invadió desde más de un año por todos lados, el potrero casi perdido... y los turistas que ya empiezan a venir y ver ruinas que no puedo justificar, ni explicar sin decir cosas que no suceden sino en el Paraguay y por tanto no pueden ser creídas, y venir a ver museo y colecciones que se pierden por parejo, por imposibilidad material de cuidarlas, en cuartuchos entregados a los insectos, a las ratas y a las avispas... el trabajo constante de 44 años. (Bertoni à Reto, 3-9 de abril de 1928, Apud BARATTI \& CANDOLFI, 1999, p.101).

De uma forma geral, ficam explícitos alguns elementos nos discursos de Bertoni que sintetizam o conjunto de ideias conhecidas sobre o avanço das fronteiras, com investimentos na agricultura, esperança no projeto da construção de uma estrada de ferro e a sua própria produção cartográfica e estudos sobre o solo e clima do Paraguai, que atrairiam mais agricultores. Em um primeiro momento, a fronteira para Bertoni era vista como algo integrado, sem conflitos com a população indígena, a ponto de, em seus escritos, apresentar o modo de vida dos Guaranis (organização familiar e a relação com a natureza) como um modelo a ser seguido.

$\mathrm{O}$ contato com as cartas proporcionou visualizar a fronteira daquele período como espaço vivo, de relações, repleto de vivências e de histórias. Por muito tempo, a literatura tradicional direcionava nosso olhar para uma fronteira marginal, como espaço vazio, inóspito e sem conhecimento. Ao contrário disso, os registros de Bertoni possuem indícios de uma movimentação intensa, principalmente no leste paraguaio, tema que mereceria especial atenção em pesquisas futuras.

\section{Considerações finais}

Tendo como base essa concepção de estudo, verificou-se que o conjunto de cartas remetidas e recebidas por Bertoni revelam ações e interações vivenciadas na fronteira. As cartas consultadas revelam não só o personagem Bertoni, mas também suas pesquisas, relações e o cuidado com a conservação dos registros para posteridade. Além disso, tais registros trazem fatos reveladores sobre o contexto da fronteira, os quais podem ser concebidos como riqueza cultural incontestável na história da fronteira.

Foram tais registros conservados que possibilitaram a pesquisa. Os atores sociais estão situados em seus contextos. Ou seja, são personagens que não somente se relacionam com outros indivíduos, mas com tudo aquilo que os rodeia, as ideias, os valores, estruturas do 
sistema, as crenças, as instituições, os recursos naturais. Bertoni, enquanto um homem da fronteira, ou fronteiriço, revela as práticas sociais e culturais desenvolvidas no território trinacional, trazendo sua própria historicidade, a partir de um espaço construído com suas ressignificações. Assim, tanto os atores que vivem ou transitam nesse espaço produzem impacto sobre o sentido da fronteira, também os sistemas interferem positivamente ou negativamente no existencial desses indivíduos que se relacionam com o território que construíram.

Bertoni vivenciou intensamente a fronteira, conheceu pessoas de várias partes do mundo, dedicou-se ao estudo da agricultura e da sociedade paraguaia, ao ponto de ter muitas experiências e com isso ele tenha sido modificado. Estas mudanças não ocorreram somente do seu modo de vida, mas na forma de conceber ou praticar sua pesquisa, principalmente sobre os Guaranis. Ao ponto de expor a concepção científica, em defesa da preservação da natureza e das populações que nela vivem. Concepção que vinha na contramão do que era planejado para a fronteira em tempos de avanço populacional e do capital aos lugares considerados "vazios".

As considerações realizadas mostraram como alguns acontecimentos, no final do século XIX e no início do XX, interferiram nas vivências de Bertoni em um contexto considerado de mudanças. Por outro lado, tais mudanças, vivências e experienciadas influenciaram a forma como Bertoni concebia a sociedade em que estava inserido e o próprio fazer científico. Tudo isso leva a pensar sobre esse tempo múltiplo vivido pelo personagem, no qual os registros apresentaram a função de uma fronteira, em que o Estado estabeleceu divisões. Esse contexto de mudanças influenciou as atividades em Puerto Bertoni, restringiu a venda dos produtos cultivados na propriedade, levando a uma crise econômica, mas também a uma crise existencial causada pela saída dos filhos da colônia, bem como a um conjunto de circunstâncias que criaram instabilidades e rearranjos nos indivíduos e nos sistemas. Tais indícios são evidenciados no conteúdo das cartas consultadas.

Muito mais do que as mudanças, que acreditamos serem inerentes em qualquer sociedade, ambiente e época, os registros produzidos por Bertoni apontaram para o lugar central que a fronteira ocupa na construção das relações e nos elementos descritos de mudanças. Pois era nesse espaço privilegiado escolhido pelo personagem, que potencializou as relações em seus diversos aspectos, que, para ele, toda a rede de conexão construída tinha uma razão principal, aquilo evidenciado como central na sua vida: as atividades científicas.

Com esta prática cultural, a de escrever, principalmente a de escrever cartas, Bertoni procurou construir uma identidade para si e de si, através de seus documentos. Nessa 
perspectiva, verifica-se que, ao escrever, exerceu uma relação com o próprio texto. Construiu imagens de si, com o intuito de materializar sua identidade. Por um lado, isso nos faz perceber que Bertoni é uma invenção do seu próprio texto, sendo um produto que ele próprio elaborou. Mas ele também vem a ser construções variadas daqueles que o interpretam, não tendo ele controle permanente sobre si. Estamos, portanto, diante de um Bertoni cambiante, mas persistente, e em constante disputa na construção de memórias. 


\section{Referências}

BARATTI \& CANDOLFI (1996). Catálogo del Archivo de Moisés Santiago Bertoni Y Familia - Puerto Bertoni, Bellinzona, Archivo Cantonal.

BARATTI \& CANDOLFI (1994). l'Arca di Mosè. Biografia epistolare di Mosè Bertoni 1857-1929. Editora Casagrande, Bellinzona, Suíça, 1 ed.

BEZERRA, Carlos Eduardo e SILVA, Telma Maciel da (2009). Jogo de cartas: a correspondência como fonte de pesquisa. Patrimônio e Memória. UNESP - FCLAs CEDAP, Vol. 5, n. 2 p. 133-158 - dez.

GINZBURG, Carlo (2007). O Fio e os Rastros: Verdadeiro, Falso, Fictício. São Paulo: Companhia das Letras, 2007.

GOMES, Ângela Casto (2004). (Org.) A Escrita de Si a Escrita da História. Rio de Janeiro: Editora FGV.

HORTA, Nicole Marinho; DIAS, Débora de Almeida; CORDEIRO, Luciana Coutinho (2018). Cartas: um acervo de memória afetiva e histórica e a importância de sua preservação. Múltiplos olhares em ciência da informação. V. 8 n. 1, mar.

MARTINS, Vanessa Gandra Dutra (2019). Reflexões sobre a escrita epistolar como fonte histórica a partir da contribuição da teoria da literatura. revistas.fw.uri.br/index.php/revistalinguaeliteratura/article/view/152, acessado em $13 / 08 / 2019$.

MATTOS, Raimundo César de Oliveira (2010). As cartas revelam - Analisando o oitocentos através da correspondência. XIV Encontro Regional da ANPHU - Memória e Patrimônio. RJ, UNIRIO.

MONTE, Vanessa Martins do (2015). Correspondências paulistas: as formas de tratamento em cartas de circulação pública (1765-1775). SP, FAPESP, Humanistas, 519 páginas.

MUNHÓS, Fernando (2016). As cartas também constroem a história: potencialidades em uma conversa vinda do passado. Revista do Instituto de Estudos Brasileiros. N. 64. Ago. p. 336342.

SILVA, Francisco Ribeiro da (1997). Coronel Helder Ribeiro - Correspondência recebida (1902-1931) e notas autobiográficas. Porto, Universidade Portucalense / Liga dos Amigos do Museu Militar do Porto.

SILVA, Victória Gambetta da (2007). Resenha. A Escrita de Si e a Escrita da História. Revista História em Reflexão: Vol. 1 n. 1 - UFGD - Dourados Jan/Jun. 